\title{
Attribution Analysis of Runoff Variation in the Yue River Watershed of the Qinling Mountains
}

\author{
Yiyi Hu $\mathbb{D}^{1,2,3}$ and Yi He $\mathbb{i}^{1,2,3}$ \\ ${ }^{1}$ Shaanxi Key Laboratory of Earth Surface System and Environmental Carrying Capacity, \\ College of Urban and Environmental Sciences, Northwest University, Xi'an 710127, China \\ ${ }^{2}$ Institute of Qinling Mountains, Northwest University, Xi'an 710127, China \\ ${ }^{3}$ Yellow River Institute of Shaanxi Province, Xi'an 710127, Shaanxi, China \\ Correspondence should be addressed to Yi He; yihe@nwu.edu.cn
}

Received 5 September 2021; Revised 1 December 2021; Accepted 7 December 2021; Published 22 December 2021

Academic Editor: Gwo-Fong Lin

Copyright (c) 2021 Yiyi Hu and Yi He. This is an open access article distributed under the Creative Commons Attribution License, which permits unrestricted use, distribution, and reproduction in any medium, provided the original work is properly cited.

\begin{abstract}
In recent decades, global climate change, especially human activities, has led to profound changes in the hydrological cycle and hydrological processes in watersheds. Taking the Yue River watershed in the Qinling Mountains in China as the study area, the Mann-Kendall test and Pettitt mutation test method were used to analyze the various characteristics of hydrological and climatic elements from 1960 to 2018. Then, the elastic coefficient method based on the Budyko framework was used to estimate the elastic coefficient of runoff change on each influencing factor. The results showed that the annual runoff decreased at a rate of $0.038 \times 10^{8} \mathrm{~m}^{3} / \mathrm{a}(P>0.05)$, and a significant abrupt change occurred in 1990 . The annual precipitation and potential evapotranspiration $\left(\mathrm{ET}_{0}\right)$ increased and decreased, with change rates of $0.614 \mathrm{~mm} / \mathrm{a}$ and $-0.811 \mathrm{~mm} / \mathrm{a}(P>0.05)$, respectively. The elasticity coefficients of precipitation, $\mathrm{ET}_{0}$, and the underlying surface were $1.95,-0.95$, and -0.85 , respectively, indicating that annual runoff was most sensitive to the change in precipitation, followed by the change in $\mathrm{ET}_{0}$, and had the lowest sensitivity to the change in the underlying surface. Underlying surface change is the main factor of runoff decrease; the contribution is $89.07 \%$. The total contribution of climate change to runoff change is $10.93 \%$, in which the contributions of precipitation and $\mathrm{ET}_{0}$ are $17.59 \%$ and $-6.66 \%$, respectively. The NDVI reflecting underlying surface change has been increasing since 1990, which is an important reason for the runoff decrease.
\end{abstract}

\section{Introduction}

The sixth IPCC Climate Change Assessment report points out that the rate of warming in recent decades has not been seen in thousands of years and is occurring almost everywhere on Earth, reversing a long-term global cooling trend. High latitudes in the Northern Hemisphere are projected to warm two to four times faster than global warming levels [1]. The report also points out that global climate change is formed by the joint action of natural factors and human activities, confirming that human activity is causing extreme weather [1]. The continuous rise of global temperature accelerates the global water cycle, exacerbates extreme hydrological events, and leads to the redistribution of water resources at different scales. Runoff is one of the main sources of water available to humans. Significant changes in runoff have been observed in many regions of the world [2-5], and many studies focus on the driving factors of runoff change, among which climate change and human activities are considered to be the two major factors $[6,7]$. Climate change affects the runoff process through meteorological factors such as precipitation, temperature, and sunshine, and the influence of human activities is mainly reflected in land use and land cover change [8].

There are three main methods to quantify the impacts of climate change and human activities on runoff. The pairing watershed experiment method is limited to small watersheds and requires a large workforce and material resources [9]. The other two methods are based on hydrological models and statistical analysis [10]. The hydrological model has a good physical foundation, but it requires more data and parameter calibration [11]. Paired watershed experiments 
(including controlled and treated basins) are a classic method for quantifying the hydrological response to climate change and human activities. However, this method is only suitable for small watersheds [9]. The elasticity coefficient method based on the Budyko frame is often used in runoff change attribution because of its simple principle, certain physical basis, easy access to required data, fewer parameters, and high reliability $[3,12]$. Yang et al. [13] used the Choudhury-Yang formula to quantitatively distinguish the effects of climate change and underlying surface change on runoff in the Yellow River Basin. He et al. [14] found that the change in the underlying surface was the main reason for the decrease in runoff in the Ba River basin of the Qinling Mountains by using the Budyko framework. Xia et al. [15] quantitatively estimated the impact of climate change and human activities on runoff in the upper reaches of the Hanjiang River by using six derivative formulas of the Budyko theory.

The Qinling Mountains are the boundary between the subtropical zone and the warm temperate zone in China, and they are regarded as the symbol of the boundary between northern and southern China, which has special geographical significance. The relationship between the water cycle in the Qinling Mountains and the response of climate change and human activities and the changing pace of the water cycle in the North and the South has attracted wide attention. The Han River is the core water conservation area of the middle route of the South-to-North Water Transfer project. The Yue River is an important tributary of the upper Han River. Due to the limitations of basin physical geography, hydrometeorological data, and other conditions, there are few types of research on the attribution of runoff change in the Yue River watershed. He et al. [16] used a comparative analysis of the runoff changes in the Wei River basin and the upper reaches of the Hanjiang River and concluded that the change in the underlying surface was the main reason for the decrease in runoff. Zhang et al. [17] quantitatively analyzed the impact of human activities and precipitation changes on runoff in the Yue River watershed by establishing a statistical model of the relationship between precipitation and runoff and concluded that runoff changes were largely influenced by human activities, accounting for $62 \%$. To date, most scholars have used attribution analysis of runoff change in the Yue River watershed through statistical models, which lack a certain physical basis.

The Yue River is in the upper reaches of the Han River. Due to the impact of global warming, the runoff process has changed significantly, and the contradiction between the supply and demand of water resources has become increasingly prominent in the Yue River watershed. Therefore, it is of great practical significance to carry out attribution analysis of runoff change in the Yue River watershed for rational allocation and sustainable utilization of water resources in the watershed. In this study, the contributions of climate change and underlying surface change to runoff change in the Yue River watershed were separated and quantified using the Budyko frame, aiming to provide a theoretical basis for water resource planning and management and river ecosystem protection.

\section{Study Area and Data}

2.1. Study Region. The Yue River is a tributary of the Han River, which belongs to the Yangtze River basin and is $95.2 \mathrm{~km}$ long. The Yue River watershed is located between $108^{\circ} 26^{\prime}-109^{\circ} 00^{\prime} \mathrm{E}$ and $32^{\circ} 28^{\prime}-33^{\circ} 20^{\prime} \mathrm{N}$. The length of the flow domain is approximately $75 \mathrm{~km}$, and the surface area is $2830 \mathrm{~km}^{2}$. There are seven meteorological stations and one hydrological station in and around the watershed. The distribution of the stations and digital elevation model (DEM) is shown in Figure 1.

2.2. Data Source and Processing. For meteorological data, the monthly average temperature, monthly average maximum temperature, monthly average minimum temperature, monthly relative humidity, monthly average wind speed, monthly sunshine duration, and monthly precipitation of the above seven stations from 1960 to 2018 were selected, the data were obtained from the China Meteorological Data Network (http://data.cma.cn/), and the simple kriging spatial interpolation method was used to calculate the watershed average [2]. The runoff of Chang Qiang Pu (CQP) Station in the Yue River watershed from 1960 to 2018 was obtained from the Hydrology Bureau of the Yangtze River Water Resources Commission. The normalized differential vegetation index (NDVI) was obtained from the GIMMS NDVI dataset from 1982 to 2015 provided by NASA (https:// ecocast.arc.nasa.gov/data/pub/gimms/), and the spatial resolution was $8 \mathrm{~km}$.

\section{Methodology}

3.1. Trend and Mutation Analysis. The Mann-Kendall (M-K) test was used to analyze the trends of climate factors and runoff. The Pettitt mutation test was used to analyze the mutation of annual runoff in the Yue River watershed. The $\mathrm{M}-\mathrm{K}$ test was proposed by Mann [18] and has been widely used in trend analysis of climate and hydrological series $[19,20]$. The Pettitt mutation test [21] method is a nonparametric test method. Its principle is to construct statistics for the order column corresponding to the climate sequence, and the time corresponding to the maximum value of statistics is the possible mutation point.

\subsection{Attribution Analysis of Runoff Change}

3.2.1. Budyko Frame. Based on the Budyko frame, the elastic coefficient method estimates the climatic elastic coefficient and the underlying surface elastic coefficient, thus realizing the separation and quantification of the influence of climate change and underlying surface change on runoff [13]. Budyko theory is based on the water balance equation, whose expression is as follows:

$$
R=P-E-\Delta S,
$$

where $R$ is the average annual runoff depth $(\mathrm{mm}) ; P$ is the average annual precipitation in the watershed $(\mathrm{mm}) ; E$ is the annual average actual evapotranspiration $(\mathrm{mm})$ of the 


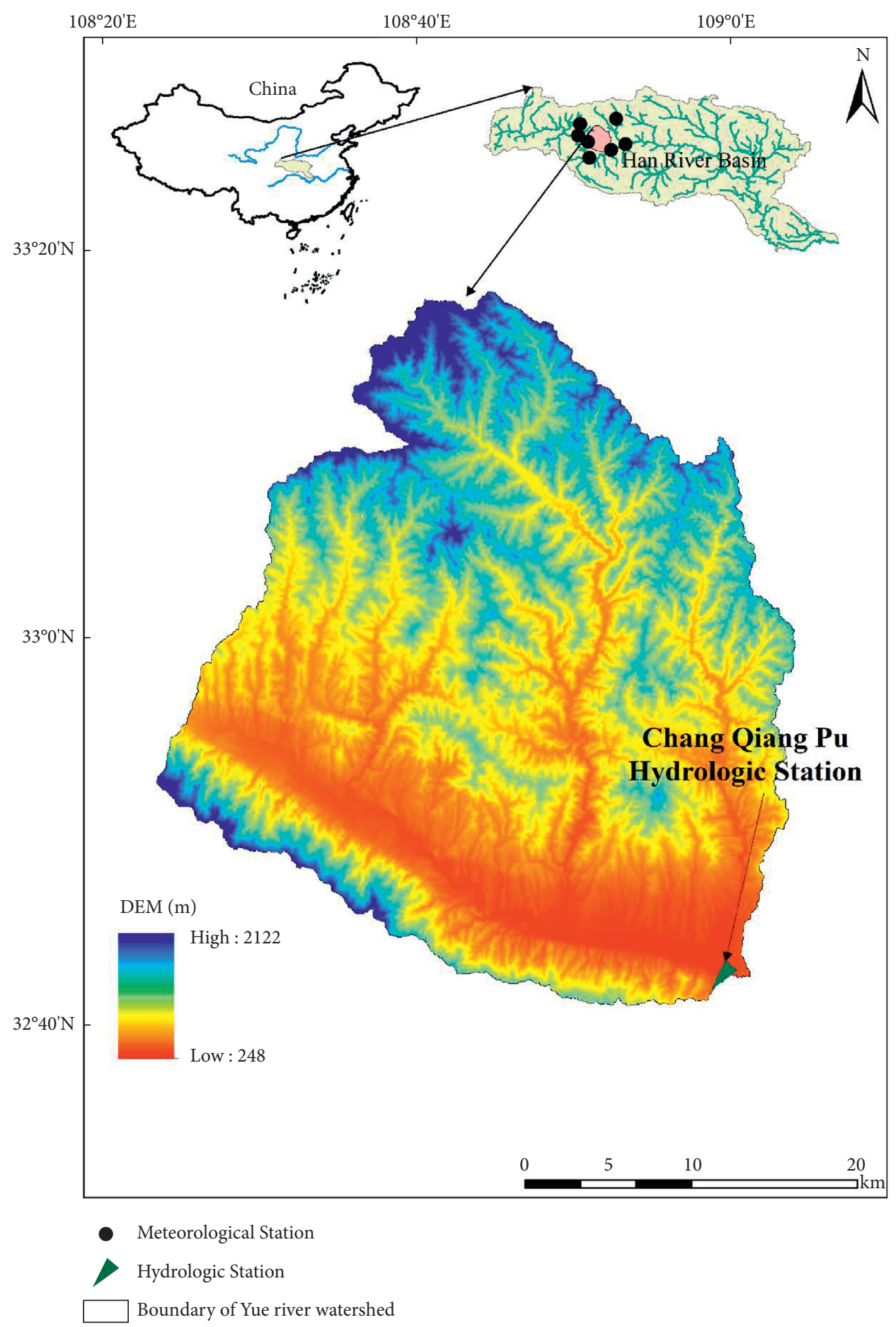

Figure 1: The location of the Yue watershed.

watershed; and $\Delta S$ is the change amount of water storage in the watershed. It is generally believed that when the analysis is on a long time scale and the watershed is a closed watershed, $\Delta S$ can be ignored.

After years of research, Budyko found that the actual evaporation on a long time scale is determined by the balance between precipitation and $\mathrm{ET}_{0}$. Based on this hypothesis, Choudhury and Yang deduced the coupled hydrothermal balance equation [22, 23] of the watershed, and its expression is as follows:

$$
E=\frac{P \times E T_{0}}{\left(P^{n}+E T_{0}^{n}\right)^{(1 / n)}},
$$

where $\mathrm{ET}_{0}$ is the annual average potential evapotranspiration $(\mathrm{mm})$ of the watershed and $n$ is the underlying surface 
parameter, which mainly reflects the underlying surface characteristics of the watershed, such as topography, soil, and vegetation. By combining equations (1) and (2), the average $\mathrm{P}, \mathrm{ET}_{0}$, and $R$ of the watershed are known and $\Delta S$ are ignored so that $n$ can be estimated.

$\mathrm{ET}_{0}$ can be calculated by the FAO Penman-Monteith formula [24], and the expression is

$$
E T_{0}=\frac{0.408 \Delta\left(R_{n}-G\right)+\gamma(900 / T+273) \mu_{2}\left(e_{s}-e_{a}\right)}{\Delta+\gamma\left(1+0.34 \mu_{2}\right)},
$$

where $\mathrm{ET}_{0}$ is the potential evapotranspiration $(\mathrm{mm}) ; \Delta$ is the slope of the saturated vapor pressure curve $\left(\mathrm{kPa} /{ }^{\circ} \mathrm{C}\right) ; R_{n}$ is the net radiation of the ground surface $\left(\mathrm{MJ} /\left(\mathrm{m}^{2} \cdot \mathrm{d}\right)\right)$; $G$ is the soil heat flux $\left(\mathrm{MJ} /\left(\mathrm{m}^{2} \cdot \mathrm{d}\right)\right) ; \gamma$ is the hygrometer constant $\left(\mathrm{kPa} /{ }^{\circ} \mathrm{C}\right)$; $T$ is the average temperature $\left({ }^{\circ} \mathrm{C}\right) ; \mu_{2}$ is the wind speed at a height of $2 \mathrm{~m}(\mathrm{~m} / \mathrm{s}) ; e_{s}$ is the saturated vapor pressure $(\mathrm{kPa})$; and $e_{a}$ is the real water vapor pressure $(\mathrm{kPa})$. In the formula, $\Delta, R_{n}, G, \gamma, e_{s}$, and $e_{a}$ can all be obtained from the monthly mean temperature, monthly mean maximum temperature, monthly mean minimum temperature, monthly relative humidity, and monthly sunshine hours of each station.

\subsubsection{Elastic Coefficient of Runoff to Climate and Underlying} Surface. According to equations (1) and (2), the equation of the watershed can be expressed as $R=f\left(\mathrm{P}, \mathrm{ET}_{0}, \mathrm{n}\right)$. The degree of influence of each influencing factor on runoff variation can be expressed by the elastic coefficient $\varepsilon$, which is expressed as

$$
\varepsilon_{x}=\frac{\partial R}{\partial x} \times \frac{x}{R}
$$

where $\varepsilon_{x}$ is the elastic coefficient of runoff change on influencing factor $x ; x$ is precipitation, $\mathrm{ET}_{0}$, or $n$; and precipitation and $\mathrm{ET}_{0}$ are the mean values of the flow domain. The elasticity coefficient is the percentage change of runoff relative to the average annual value caused by an increase in the impact factor $x$ by $1 \%$. The positive (negative) value of the elasticity coefficient indicates that the runoff increases (decreases) with the increase in the impact factor $x$. Let $\varphi=E T_{0} / P$, the precipitation elasticity coefficient $\left(\varepsilon_{p}\right), \mathrm{ET}_{0}$ elasticity coefficient $\left(\varepsilon_{E T_{0}}\right)$, and underlying surface elasticity coefficient $\left(\varepsilon_{n}\right)$ be obtained by using equation (4). The calculation formula is as follows:

$$
\begin{gathered}
\varepsilon_{P}=\frac{\left(1+\varphi^{n}\right)^{(1 / n+1)}-\varphi^{n+1}}{\left(1+\varphi^{n}\right)\left[\left(1+\varphi^{n}\right)^{(1 / n)}-\varphi\right]}, \\
\varepsilon_{E T_{0}}=\frac{1}{\left(1+\varphi^{n}\right)\left[1-\left(1+\varphi^{-n}\right)^{(1 / n)}\right]}, \\
\varepsilon_{n}=\frac{\ln \left(1+\varphi^{n}\right)+\varphi^{n} \ln \left(1+\varphi^{-n}\right)}{n\left[\left(1+\varphi^{n}\right)-\left(1+\varphi^{n}\right)^{(1 / n+1)}\right]} .
\end{gathered}
$$

3.2.3. Contribution of Influencing Factors to Runoff Change. The study period was divided into two periods by using the Pettitt mutation test. The period before the mutation was called the baseline period, and the runoff was less affected by the underlying surface and was considered to be runoff in the natural period of the watershed. The abrupt change is called the change period, and the runoff change is mainly affected by human activities. The actual runoff change from the base period to the change period can be expressed by $\Delta R$, that is,

$$
\Delta R=R_{2}-R_{1}
$$

Generally, the influence of climate change on runoff is mainly caused by changes in precipitation and $\mathrm{ET}_{0}$. Since there is no large-scale water conservancy project in the study area, the influence of human activities on runoff change can be considered to be mainly caused by the change in the underlying surface. According to the precipitation elasticity coefficient, $\mathrm{ET}_{0}$ elasticity coefficient, and underlying surface elasticity coefficient of runoff, the runoff changes caused by the corresponding influencing factors can be calculated, which can be expressed as

$$
\Delta R_{x}=\varepsilon_{x} \frac{R}{x} \Delta x,
$$

where $\Delta R_{x}$ is the runoff change caused by the impact factor $x$ and $\Delta x$ is the change amount of the impact factor $x$ in the two periods.

According to the variation in runoff caused by each influencing factor obtained by the hydrothermal coupling balance equation, the variation in runoff obtained by equation $\Delta R \prime$ is expressed as follows:

$$
\Delta R^{\prime}=\Delta R_{P}+\Delta R_{E T_{0}}+\Delta R_{n} .
$$

Therefore, the calculation formula of the contribution of each influencing factor to runoff change is as follows:

$$
C_{x}=\frac{\Delta R_{x}}{\Delta R^{\prime}}
$$

where $C_{x}$ is the contribution of runoff change caused by the impact factor $x$ and $x$ is $P, \mathrm{ET}_{0}$, or $n$.

\section{Results}

4.1. The Trends of $P, E T_{0}$, and R. From 1960 to 2018, the annual $R$ and $\mathrm{ET}_{0}$ in the Yue River watershed generally showed a decreasing trend with decreasing rates of $-1.358 \mathrm{~mm} / \mathrm{a}$ (Figure 2) and $-0.811 \mathrm{~mm} / \mathrm{a}$ (Figure 3 ), respectively, while the annual rainfall showed a slightly increasing trend with an increase of $0.614 \mathrm{~mm} / \mathrm{a}$ (Figure 4). None of them passed the significance level test of 0.05 , indicating that the downward and upward trend were insignificant. The $\mathrm{M}-\mathrm{K}$ test showed that $R$ and rainfall showed decreasing and increasing trends, respectively, from 1960 to 2018. However, the variation trend was insignificant $(P>0.05)$, while $\mathrm{ET}_{0}$ showed a significant decreasing trend $(P<0.05)$.

4.2. RunoffAbrupt Test. The Pettitt mutation test was used to detect the mutation of the annual runoff series from 1960 to 2018, and the results showed that the annual runoff had a mutation in 1990 (Figure 5). 


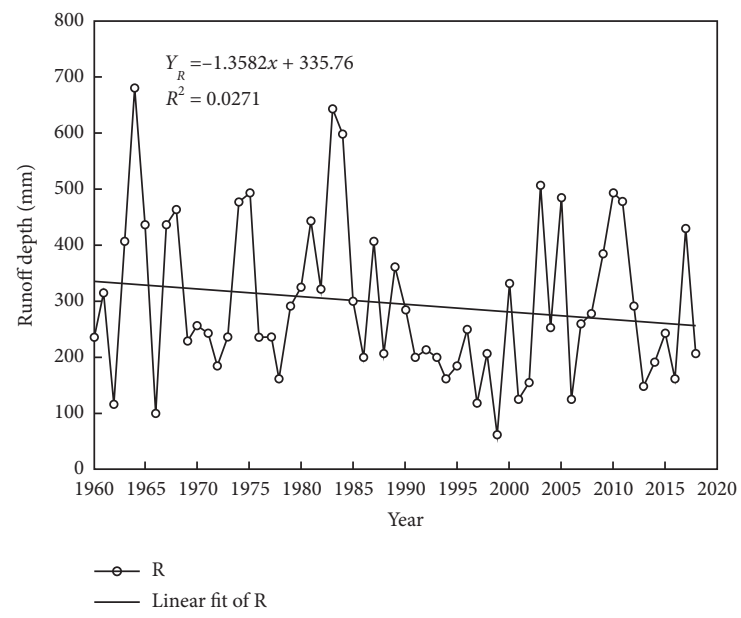

Figure 2: The variation in $\mathrm{R}$ in the Yue River watershed during 1960-2018.

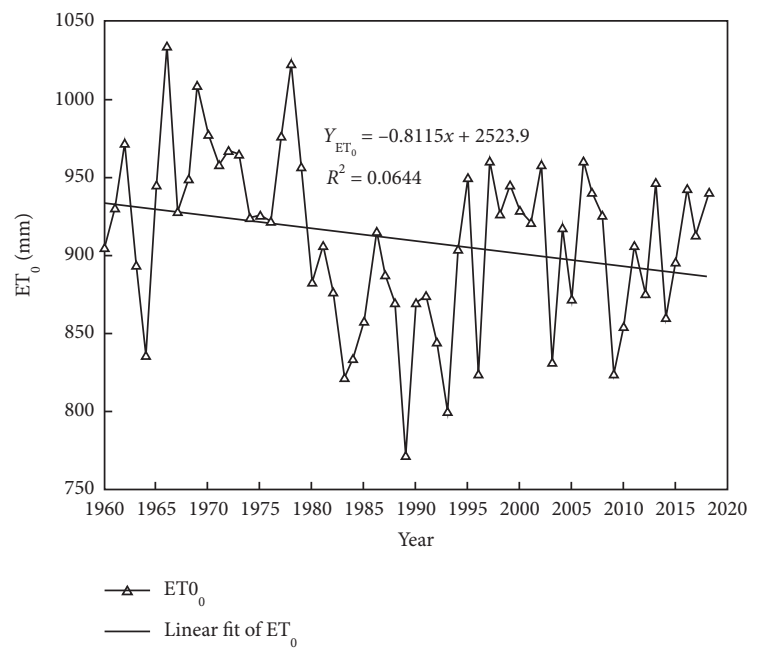

FIgURE 3: The variation in ET0 in the Yue River watershed during 1960-2018.

4.3. Elasticity of Runoff to Climatic Factors and Underlying Surface. Based on the mutation analysis results, the study period was divided into the base period (1960-1991) and the change period (1992-2018). The $R$, precipitation, and $\mathrm{ET}_{0}$ of the CQP station during the change period decreased by $23.71 \%, 2.43 \%$, and $1.90 \%$ compared with the base period, while $n$ showed an upward trend and increased by $32.62 \%$ compared with the baseline period (Table 1). Compared with the baseline period, the dryness index $\left(\mathrm{ET}_{0} / \mathrm{P}\right)$ increased slightly $(0.96 \%)$, while the runoff coefficient $(\mathrm{R} / \mathrm{P})$ decreased $23.68 \%$. The elastic coefficients $\mathrm{P}$, $\mathrm{ET}_{0}$, and $n$ of runoff on the influencing factors of the CQP station were $2.15,-1.15$, and -0.89 (Table 1 ), respectively, indicating that a $1 \%$ increase in $\mathrm{P}, \mathrm{ET}_{0}$, and $n$ would increase the $R$ by $2.15 \%$, decrease by $1.15 \%$, and decrease by $0.89 \%$, respectively. Therefore, the change in $R$ at the CQP station is positively correlated with rainfall and negatively correlated with $\mathrm{ET}_{0}$ and $n$ changes. Since the absolute value of the elastic coefficient reflects the sensitivity of runoff to the influencing factors, runoff in the Yue River watershed is the most sensitive to rainfall and the least sensitive to underlying surface changes.

4.4. Attribution of Runoff Variation. The $R$ variations caused by $\mathrm{P}, \mathrm{ET}_{0}$, and $n$ changes are $-14.19 \mathrm{~mm}, 5.38 \mathrm{~mm}$, and $-71.88 \mathrm{~mm}$, respectively. Therefore, the $R$ variation calculated based on the Budyko frame is $-80.7 \mathrm{~mm}$, while the actual $R$ variation in the study area is $-78.7 \mathrm{~mm}$, and the error between the two is $-2.00 \mathrm{~mm}$ (Table 2), indicating that the elastic coefficient method based on the Budyko framework is suitable for the attribution of runoff change in the study area. Both $\mathrm{P}$ and $n$ changes had a positive contribution to runoff change in the study area, with $17.59 \%$ and $89.07 \%$, respectively, while $\mathrm{ET}_{0}$ had a negative contribution to runoff change, with a contribution of $6.66 \%$ (Table 2). Therefore, the change in the underlying surface is the main factor causing the decrease in runoff in the Yue River watershed.

\section{Discussion}

The abrupt change in runoff in the Yue River watershed obtained in this study occurred in 1990, which is the same as that of Zhang et al. [17], since the research period of this study is 1960-2018, while that of Zhang et al. [17] is 1960-2010, and the research methods used are different (that is, this study is based on the Budyko hypothesis, while Zhang et al. [17] used a statistical model); therefore, in terms of the contribution of the underlying surface to runoff in the Yue River watershed, $89 \%$ is obtained in this study, while $62 \%$ is obtained in the study of Zhang et al. [17], and the results are different.

Studies have shown that the underlying surface parameter $n$ is mainly related to soil, topography, and vegetation $[25,26]$. On the long time scale, the factors of soil and topography are stable, and the changes in underlying surface parameters are mainly related to the changes in vegetation. Therefore, to further study the effect of underlying surface change on runoff, NDVI was used to analyze the vegetation cover change in the Yue River watershed. 


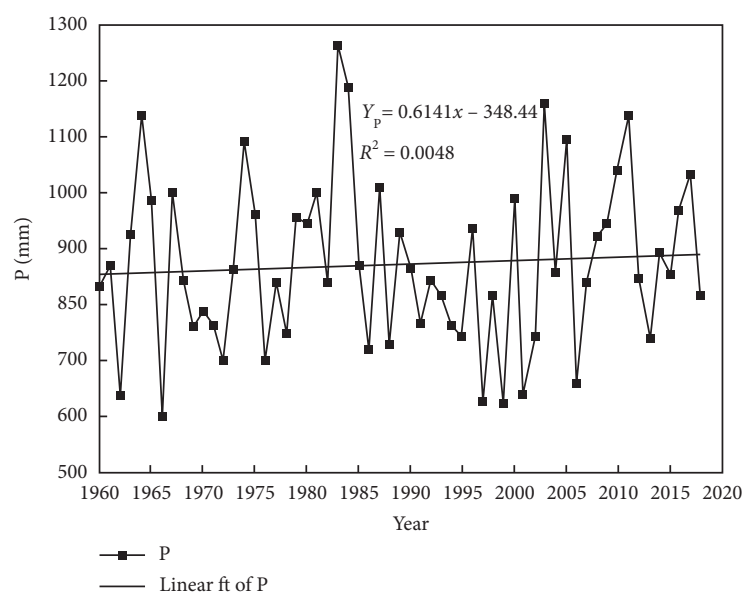

FIgURE 4: The variation in precipitation in the Yue River watershed during 1960-2018.

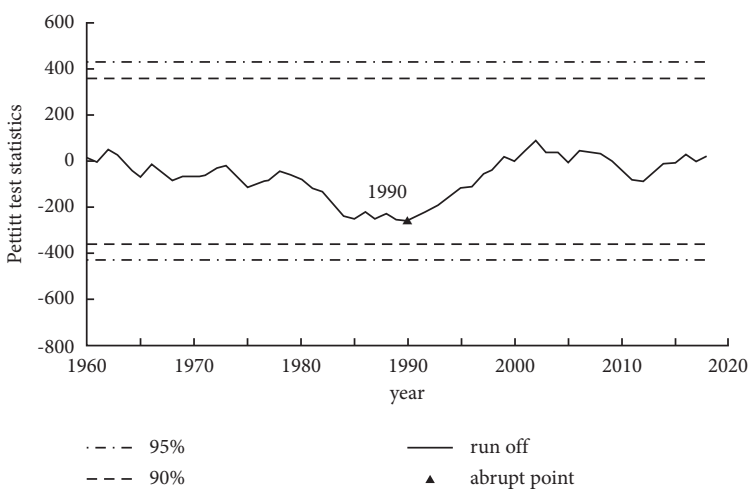

FIgURE 5: Abrupt change in annual runoff in the Yue River watershed during 1960-2018.

Table 1: Hydrometeorological characteristic values in the Yue River watershed.

\begin{tabular}{lcccccccccc}
\hline \multirow{2}{*}{ Watershed } & \multirow{2}{*}{ Period } & $R$ & $P$ & \multicolumn{2}{c}{$\mathrm{ET}_{0}$} & \multirow{2}{*}{$R / P$} & \multicolumn{2}{c}{ ET0/P } & \multicolumn{2}{c}{ Elasticity coefficients } \\
& & $\mathrm{mm}$ & $\mathrm{mm}$ & $\mathrm{mm}$ & - & - & - & $\varepsilon_{p}$ & $\varepsilon_{\mathrm{ET}_{0}}$ & $\varepsilon_{n}$ \\
\hline \multirow{2}{*}{ Yue River } & Period I (1960-1990) & 332.4 & 883.3 & 918.2 & 1.41 & 0.38 & 1.04 & 1.81 & -0.81 \\
& Period II (1991-2018) & 253.6 & 861.8 & 900.7 & 1.87 & 0.29 & 1.05 & 2.15 & -1.15 & -0.81 \\
& & &
\end{tabular}

Note: $R$ represents runoff depth; $\mathrm{P}$ represents precipitation; $\mathrm{ET}_{0}$ represents potential evapotranspiration; $n$ represents underlying surface feature parameters; $\mathrm{R} / \mathrm{P}$ represents runoff coefficient; $\mathrm{ET}_{0} / \mathrm{P}$ represents drought index; $\varepsilon_{\mathrm{p}}$ represents elasticity coefficient of precipitation; $\varepsilon_{\mathrm{ETo}}$ represents elasticity coefficient of $\mathrm{ET}_{0}$, and $\varepsilon_{n}$ represents elasticity coefficient of underlying surface feature parameters.

TABLE 2: Attribution of runoff change in the Yue River watershed.

\begin{tabular}{cccccccccc}
\hline Watershed & $\triangle R_{p}(\mathrm{~mm})$ & $\Delta R_{\mathrm{ET}_{0}}(\mathrm{~mm})$ & $\Delta R_{n}(\mathrm{~mm})$ & $\triangle R(\mathrm{~mm})$ & $\triangle R^{\prime}(\mathrm{mm})$ & $\delta(\mathrm{mm})$ & $C_{P}(\%)$ & $C_{\mathrm{ET}_{0}}(\%)$ & $C_{n}(\%)$ \\
\hline Yue River & -14.19 & 5.38 & -71.88 & -78.7 & -80.7 & -2.00 & 17.59 & -6.66 & 89.07 \\
\hline
\end{tabular}

Note: $\triangle R_{p}$ represents changes in runoff caused by changes in $P ; \triangle \mathrm{R}_{\mathrm{ET} 0}$ represents changes in runoff caused by changes in $\mathrm{ET}_{0} ; \triangle R_{n}$ represents changes in runoff caused by changes in $n ; \triangle \mathrm{R}$ represents actual runoff depth; $\triangle R^{\prime}$ represents calculated runoff depth; $\delta$ represents the difference between $\triangle R^{\prime}$ and $\triangle R ; C_{P}$ represents the contribution of $\mathrm{P}$ to runoff change; $C_{\mathrm{ETO}}$ represents the contribution of $\mathrm{ET}_{0}$ to runoff change; $C_{n}$ represents the contribution of $n$ to runoff change.

The NDVI values showed an increasing trend in the base period, with an increasing rate of $0.023 /(10 a)(P>0.05)$ (Figure 6), and the rising rate increased to $0.027 /(10 \mathrm{a})$ $(P<0.05)$ during the change period. Since runoff changes occurred in 1990, the NDVI was divided into 1982-1990 and 1991-2015. The average NDVI from 1982 to 1990 was 0.815 , while the average NDVI from 1991 to 2015 was 0.846
(Figure 6). The spatial distribution of NDVI differences between 1991-2015 and 1982-1990 showed that only $2.63 \%$ of NDVI decreased compared with 1982-1990, indicating an overall increase in vegetation coverage in the Yue River watershed (Figure 7). Vegetation can block surface runoff, increase infiltration time, and improve the soil, making the soil texture more porous and increasing infiltration, 


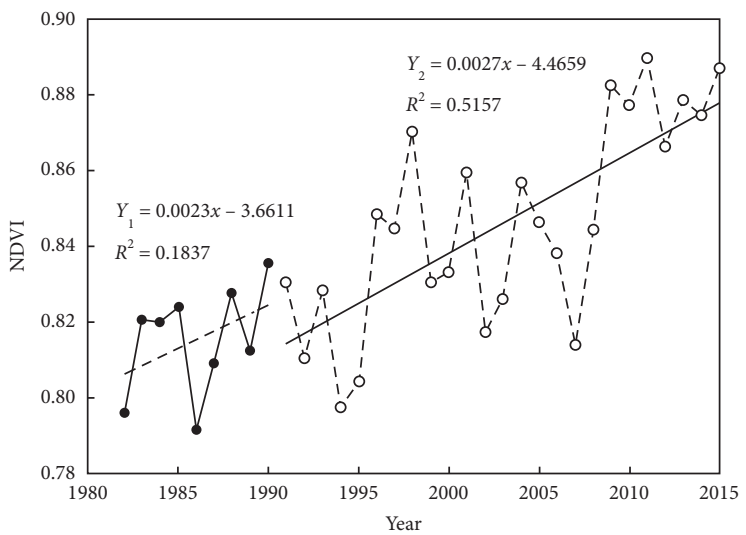

Figure 6: Variation in NDVI in the Yue River watershed during 1982-2015.

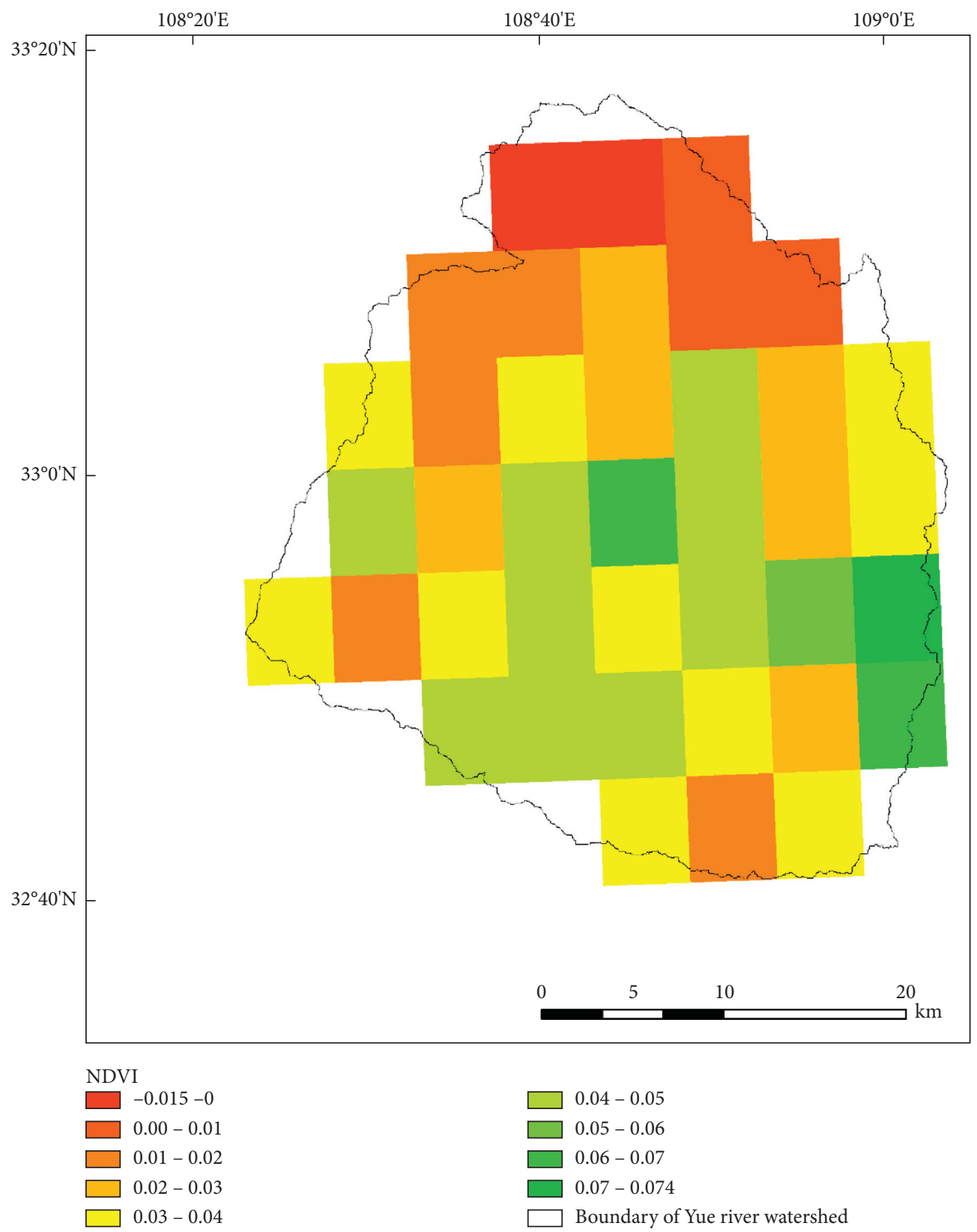

FiguRE 7: Different NDVIs between 1982-1990 and 1991-2015. 
resulting in reduced runoff. Studies [27] have shown that a series of ecological restoration policies in China have increased vegetation coverage, which is one of the important reasons for the decrease in runoff in many river basins in China.

\section{Conclusions}

Based on the Budyko frame, this study used the Man$\mathrm{n}$-Kendall test method and the Pettitt mutation test method to quantitatively analyze the effects of climate change and underlying surface change on runoff change in the Yue River watershed. The research conclusions are as follows:

(1) During 1960-2018, $R$ showed a decreasing trend $(P>0.05)$, with a rate of change of $1.358 \mathrm{~mm} / \mathrm{a}$, and an abrupt change occurred in 1990. $P$ showed an increasing trend with a change rate of $0.614 \mathrm{~mm} / \mathrm{a}$ $(P>0.05)$, and $\mathrm{ET}_{0}$ showed a downward trend with a change rate of $0.811 \mathrm{~mm} / \mathrm{a}(P>0.05)$.

(2) The elasticity coefficients of $P, \mathrm{ET}_{0}$, and $n$ are 1.95 , -0.95 , and -0.85 , respectively, indicating that annual runoff change is the most sensitive to $P$, followed by $\mathrm{ET}_{0}$, and has the lowest sensitivity to $n$.

(3) Underlying surface change is the main factor of runoff increase; the contribution is $89.07 \%$. The total contribution of climate change to runoff change is $10.93 \%$, in which the contributions of $P$ and $\mathrm{ET}_{0}$ are $17.59 \%$ and $-6.66 \%$, respectively.

(4) From 1982 to 2015, NDVI showed an increasing trend. The vegetation coverage gradually increased, which became an important factor leading to runoff reduction in the Yue River watershed.

\section{Data Availability}

For meteorological data, the monthly average temperature, monthly average maximum temperature, monthly average minimum temperature, monthly relative humidity, monthly average wind speed, monthly sunshine duration, and monthly precipitation of the above seven stations from 1960 to 2018 were selected, the data were obtained from the China Meteorological Data Network (http://data.cma.cn/), and the simple kriging spatial interpolation method was used to calculate the watershed average [2]. The runoff of Chang Qiang Pu (CQP) Station in the Yue River watershed from 1960 to 2018 was obtained from the Hydrology Bureau of the Yangtze River Water Resources Commission. Normalized Differential Vegetation Index (NDVI) was obtained from the GIMMS NDVI dataset from 1982 to 2015 provided by NASA (http://data.tpdc.ac.cn/en/data); the spatial resolution was $8 \mathrm{~km}$.

\section{Conflicts of Interest}

The authors declare that there are no conflicts of interest regarding the publication of this study.

\section{Acknowledgments}

This research was jointly supported by the National Science and Technology Basic Resource Investigation Project (Grant no. 2017FY100904), China Postdoctoral Science Foundation (Grant no. 2018M633602), Postdoctoral Research Fund of Shaanxi Province (Grant no. 2017BSHEDZZ144), and the Natural Science Basic Research Plan in Shaanxi Province of China (Grant no. 2021JQ-449).

\section{References}

[1] IPCC, "Summary for policymakers," in Climate Change 2021: The Physical Science Basis Contribution of Working Group I to the Sixth Assessment Report of the Intergovernmental Panel on Climate Change [Masson-Delmotte, V., P. Zhai, A. Pirani, S. L. Connors et al., Eds., Cambridge University Press, Cambridge, UK, 2021.

[2] Y. He, F. Wang, X. M. Mu, H. T. Yan, and G. J. Zhao, “An assessment of human versus climatic impacts on jing river basin, loess plateau, China," Advances in Meteorology, vol. 2015, Article ID 478739, 13 pages, 2015.

[3] Y. He, J. Song, Y. Hu, X. Tu, and Y. Zhao, "Impacts of different weather conditions and landuse change on runoff variations in the beiluo river watershed, China," Sustainable Cities and Society, vol. 50, Article ID 101674, 2019.

[4] G. Q. Wang, J. Y. Zhang, X. X. Guan et al., "Quantifying attribution of runoff change for major rivers in China," Advances in Water Science, vol. 31, no. 3, pp. 313-323, 2020, Chinese.

[5] D. Mengistu, W. Bewket, A. Dosio, and H. J. Panitz, "Climate change impacts on water resources in the upper blue nile (abay) river basin, Ethiopia," Journal of Hydrology, vol. 592, p. 125614, 2020.

[6] S. Piao, P. Ciais, Y. Huang et al., "The impacts of climate change on water resources and agriculture in China," Nature, vol. 467, no. 7311, pp. 43-51, 2010.

[7] Y. He, F. Wang, P. Tian et al., "Impact assessment of human activities on runoff and sediment of Beiluo River in the Yellow River Based on paired years of similar climate," Polish Journal of Environmental Studies, vol. 25, no. 1, pp. 121-135, 2016.

[8] Y. He, F. Wang, X. M. Mu, L. Q. Guo, P. Gao, and G. J. Zhao, "Human activity and climate variability impacts on sediment discharge and runoff in the Yellow River of China," Theoretical and Applied Climatology, vol. 129, no. 1-2, pp. 645-654, 2017.

[9] A. E. Brown, L. Zhang, T. A. McMahon, A. W. Western, and R. A. Vertessy, "A review of paired catchment studies for determining changes in water yield resulting from alterations in vegetation," Journal of Hydrology, vol. 310, no. 1-4, pp. 28-61, 2005.

[10] M. Shahid, Z. T. Cong, and D. W. Zhang, "Understanding the impacts of climate change and human activities on streamflow: a case study of the Soan River basin, Pakistan," Theoretical and Applied Climatology, vol. 134, no. 1-2, pp. 205-219, 2018.

[11] A. Sood and V. Smakhtin, "Global hydrological models: a review," Hydrological Sciences Journal, vol. 60, no. 4, pp. 549-565, 2015.

[12] Y. He, X. Jiang, N. Wang et al., "Changes in mountainous runoff in three inland river basins in the arid Hexi Corridor, China, and its influencing factors," Sustainable Cities and Society, vol. 50, Article ID 101703, 2019. 
[13] D. W. Yang, S. L. Zhang, and X. Y. Xu, "Attribution analysis for runoff decline in Yellow River Basin during past fifty years based on Budyko hypothesis," Scientia Sinica, vol. 45, no. 10, pp. 1024-1034, 2015, Chinese.

[14] Y. He, H. Qiu, J. Song et al., "Quantitative contribution of climate change and human activities to runoff changes in the Bahe River watershed of the Qinling Mountains, China," Sustainable Cities and Society, vol. 51, Article ID 101729, 2019.

[15] J. Xia, X. Y. Ma, L. Zou, Y. L. Ma, and Z. X. Jing, "Quantitative analysis of the effects of climate change and human activities on runoff in the Upper Hanjiang river basin," South-to-North Water Transfers and Water Science \& Technology, vol. 15, no. 1, pp. 1-6, 2017, Chinese.

[16] Y. He, Y. Hu, J. Song, and X. Jiang, "Variation of runoff between southern and northern China and their attribution in the Qinling Mountains, China," Ecological Engineering, vol. 171, Article ID 106374, 2021.

[17] X. L. Zhang, L. M. Huang, and B. Shen, "Characteristics of runoff and its responses to rainfall change in typical basins of northern and southern regions of Qinling Mountains," Water Resources and Power, vol. 30, no. 1, pp. 11-14, 2015, Chinese.

[18] H. B. Mann, "Nonparametric tests against trend," Econometrica, vol. 13, no. 3, pp. 245-259, 1945.

[19] Y. He, X. Mu, P. Gao et al., "Trends, periodicities and discontinuities of precipitation in the huangfuchuan watershed, loess plateau, China," Current Science, vol. 111, no. 4, pp. 727-733, 2016.

[20] Y. He, P. Tian, X. M. Mu et al., "Changes in daily and monthly rainfall in the middle Yellow River, China," Theoretical and Applied Climatology, vol. 129, no. 1-2, pp. 139-148, 2017.

[21] A. N. Pettitt, "A non-parametric approach to the changepoint problem," Applied Statistics, vol. 28, no. 2, pp. 126-135, 1979.

[22] B. Choudhury, "Evaluation of an empirical equation for annual evaporation using field observations and results from a biophysical model," Journal of Hydrology, vol. 216, no. 1, pp. 99-110, 1999.

[23] H. B. Yang, D. W. Yang, Z. D. Lei, and F. B. Sun, "New analytical derivation of the mean annual water-energy balance equation," Water Resources Research, vol. 44, no. 3, Article ID W03410, 2008.

[24] R. G. Allen, L. S. Pereira, D. Raes, and M. Smith, "Crop evapotranspiration guidelines for computing crop water requirements," FAO Irrigation and Drainage Paper no. 56, FAO, Rome, Italy, 1998.

[25] P. C. D. Milly, "Climate, soil water storage, and the average annual water balance," Water Resources Research, vol. 30, no. 7, pp. 2143-2156, 1994.

[26] D. W. Yang, F. B. Sun, Z. Y. Liu, Z. T. Cong, G. H. Ni, and Z. D. Lei, "Analyzing spatial and temporal variability of annual water-energy balance in nonhumid regions of China using the Budyko hypothesis," Water Resources Research, vol. 43, no. 4, Article ID W04426, 2007.

[27] S. L. Zhang, D. W. Yang, H. B. Yang, and H. M. Lei, "Analysis of the dominant causes for runoff reduction in five major basins over China during 1960-2010," Advances in Water Science, vol. 26, no. 5, pp. 605-613, 2015, Chinese. 